CORRESPONDENCE

\title{
Comment on: 'Is undergraduate ophthalmology teaching in the United Kingdom still fit for purpose?'
}

(c) The Author(s), under exclusive licence to The Royal College of Ophthalmologists 2022

Eye (2022) 36:2216; https://doi.org/10.1038/s41433-022-01976-w

\section{TO THE EDITOR}

Thank you to the authors of the article 'Is undergraduate ophthalmology teaching in the United Kingdom still fit for purpose?' for an interesting perspective on how to improve the undergraduate student experience within ophthalmology [1]. The authors conclude that the use of technology and blended learning within undergraduate ophthalmology teaching will improve the knowledge and engagement of students. I believe it is also worth noting that the blended approach to teaching, rather than previous didactic formats, may also increase awareness and interest in ophthalmology as a career.

It is known that future career choices are influenced by the length of experience within a specialty at medical school [2]. As an Undergraduate Clinical Teaching Fellow, I can appreciate the immense impact COVID-19 has had on medical education. Medical schools during the pandemic suspended clinical placement and face-to-face teaching [3]. When students did return to hospitals, emphasis was on catching up with core medical and surgical placements. Although clinical placements have now recommenced, opportunities are still limited. Some Trusts are unable to run full ophthalmology theatre lists and may be running clinics under increased time pressure. Consequently, medical students have had very little educational exposure to ophthalmology over the past 18 months. There are some medical students that may never even get to see the most commonly performed surgical procedure in the United Kingdom; a cataract operation [4].

Blended learning techniques help address the likely long-term impact of COVID-19 on ophthalmological exposure and subsequent interest in the specialty. It is likely to increase interest in those considering it as a career choice, but also those within allied specialties that frequently treat ophthalmological patients; for example, general practitioners who may then consider extended ophthalmology roles.

By adopting technology within blended learning, it is likely to attract more technologically inclined applicants. As technology continues to play an increasing role in healthcare provision, this passion within a workforce is likely to become hugely beneficial in advancing the specialty.

To conclude, adopting a blended learning approach in ophthalmology undergraduate education is likely to improve medical students' interest in the specialty and subsequent career choice.

\author{
Lois Crabtree ${ }^{1 凶}$ \\ ${ }^{1}$ Epsom and St Helier University Hospitals, University Hospitals \\ Sussex, NHS Foundation Trust, Epsom, UK. \\ 凶email: lois.crabtree1@nhs.net
}

\section{REFERENCES}

1. Scantling-Birch $Y$, Naveed $H$, Tollemache $N$, Gounder $P$, Rajak S. Is undergraduate ophthalmology teaching in the United Kingdom still fit for purpose?. Eye. 2021;36:343-5.

2. Dean $S$, Javed $M$, Jones $N$. Factors influencing a career choice in plastic surgery as a UK medical student. PMFA J. 2016:3:1-5.

3. Hunter J, Murdoch S. Cancelled medical student placements: the COVID-19 effect. Postgrad Med J. 2020;96:434-5.

4. Donachie PHJ, Sparrow JM. National ophthalmology database audit. United Kingdom: The Royal College of Ophthlamologists; 2020.

\section{COMPETING INTERESTS}

The author declares no competing interests.

\section{ADDITIONAL INFORMATION}

Correspondence and requests for materials should be addressed to Lois Crabtree.

Reprints and permission information is available at http://www.nature.com/ reprints

Publisher's note Springer Nature remains neutral with regard to jurisdictional claims in published maps and institutional affiliations. 